\title{
Communicating Mega Events on Twitter: Implication for Destination Marketing
}

\author{
Xin (Cathy) Jin* \\ Department of Tourism, Sport and Hotel Management \\ Griffith University \\ Gold Coast Campus, 4222, QLD, Australia \\ Tel: +61 755529290 Fax: +61 55528507 \\ Email: x.jin@griffith.edu.au \\ Mingming Cheng \\ School of Marketing, Curtin Business School \\ Curtin University, Australia \\ Tel | +61892661256 \\ Email: mingming.cheng@,curtin.edu.au
}

Note: * corresponding author

This paper has not been published elsewhere and has not been submitted simultaneously for publication elsewhere.

\begin{abstract}
:
Guided by social network analysis, this paper examines the communication of the Commonwealth Games on Twitter and paints a picture of the roles and relations of the key contributors and formation of networks arising out of this mega event context. The findings provide important implications for event marketing and event-based destination marketing. Event organizations and host cities must understand the co-creative capacity of the key influencers and re-invent their own communication design for engagements with these key influencers at different event stages for co-creation of events to gain economic and noneconomic benefits for both the organization and the destination.
\end{abstract}

Key words: Social Media; Stakeholder; Social Network Analysis; Event; Twitter 


\section{Introduction}

The increasing use of social media among the global population has made social media an indispensable part of organizations and individuals, where all the parties could co-create values (Cheng \& Foley 2018; Lund, Cohen, \& Scarles 2018). The power of social media not only lies on its connectiveness but also its influence over one other's perception and behaviour by facilitating both relational and dialogic models of communication (Macnamara \& Zerfass 2012). Research shows that effective and efficient social media communication of an organization can increase the organizations' public awareness, engagement and trust, driving brand values and reputation (Macnamara \& Zerfass 2012; Saffer, Sommerfeldt, \& Taylor 2013). This creates on-going challenges for businesses to channel its information in social media where brands are being built, shared and enhanced on different stakeholders' input (Lund, Cohen, \& Scarles 2018).

A key research topic in marketing and public relation is to understand how social media communication drive values for organizations with the recognition of the multiple stakeholders' contribution to social media communication (Lovejoy, Waters, \& Saxton 2012; Macnamara \& Zerfass 2012; Rybalko \& Seltzer 2010; Saffer, Sommerfeldt, \& Taylor 2013). While ample research has offered useful insights in general marketing and public relation context, less is known on how social media communication is driven in the tourism and event context.

Event marketing is different from general product or service marketing due to the unique characteristics of events and its involvement with multiple stakeholder groups in the planning and delivery process. In the marketing of general products and services, the marketers usually are the owners, manufacturers or distributors of the products or services. However, events have a more complex producing and distributing model. Events experience as a product is transient in nature, simultaneously produced and consumed. An event could be 
owned, marketed and produced by different entities. The consumers of an event (i.e., event attendees) are also contributors/producers as attendee-to-attendee interaction is an important part of the event (Matthews, 2016). Furthermore, events and tourism are interconnected. Events bring economic and non-economic benefits to a host location, while destination attractiveness forms a crucial factor for event success. Thus, the destination management organisation (DMO) becomes a key stakeholder even if DMO is not directly involved in the production of an event. Although event-based destination marketing motivates host locations to invest in events, event marketing usually fails to incorporate a successful destination marketing plan. This lack of collaboration and coordination is a key failure factor when destinations aim to use events for its destination marketing (Wang \& Jin, 2019). The distinct features of events and involvement of multiple stakeholders in its production, particularly a mega event, request marketing to be conducted with collaboration between various key stakeholders of the event due to this nexus between a mega event operation and the tourism development of the host location (Wang \& Jin 2019). In the context of social media marketing, unlike the two-way communication model between producers and customers for general products or services, event communication and marketing on social media demonstrate a complicated network among key stakeholder groups, involving at least the event brand owners, the producers, the marketers, the destination, and other key stakeholder groups. Yet, empirical studies are limited in theorizing such practices.

This paper aims to advance the theoretical understanding of social media communication in the nexus between event and tourism through the examination of the multiple, complex, and interdependent relationships of a mega event. Using the Commonwealth Games as a research setting, this paper examines the social media communication process of the Games by its multiple stakeholders on Twitter, a key social media site for events social media 
communication. Guided by social network analysis (SNA), this paper examines the formulation process of social network communication by visualizing key stakeholders and their positions in the network and assessing how connectiveness is formed. Key research questions include:

- How communication network among stakeholders on social media is structured in a mega event context?

- How does this network structure evolve over time?

- Who are the key influencers in this network and how do they impact event communication network?

By doing so, this paper provides implications to event organizations (event brand owners and contributors) and destination marketing organizations (DMOs) on ways for deliberating collaborations to enhance social media communication for management and branding purposes for both the event and the host destination.

\section{Literature review}

With the aim to advancing the theoretical understanding of stakeholder network, contribution, and position via social media communication in the context of mega events, relevant key concepts are reviewed. This section starts with discussing the nexus between event and the host destination as well as stakeholder structure and involvement in event implementation and branding. This is followed by a review on social media communication in general marketing, outlining the absence of empirical research in the event context. Last, social network analysis (SNA) and how it is employed in research is reviewed to provide rationale of using this approach for this study. 
Mega events, stakeholders, and event brand

Mega-events contribute to the host destination in both economic and non-economic terms. Values a mega event brings to the host organization as well as the host location include allocated resources, increased market segments, and an enhanced destination image, while the event experience brings a significantly positive effect on event attendees' trip value, which subsequently impact on destination loyalty and event bundling (Xu, Wong, Tan 2016). These values are co-created by various stakeholders. Co-branding is widely exercised in this framework, and research has especially examined co-branding between a mega event and its sponsors (e.g., Chalip, Green, \& Hill 2003; Washburn, Till, \& Priluck 2000) and how mega sports events such as the Olympic Games shape or enhance destination image held by the global audience (e.g., Brown, Chalip, Jago, \& Mules 2002, Li \& Kaplanidou 2013). Multiple stakeholders partaking in the planning and delivery of a mega-event complicates event planning and implementation, as well as its associated marketing outcomes (Wang \& Jin 2019).

Contrary to product or services marketing, event marketing is an under-researched area, due to its relative recency and the factors that influence its process, such as its multiple scale (e.g., mega, hallmark, regional events), distinctive types (e.g., sports, festivals, businesses, government), and the complication of event ownership by its stakeholders (Wang \& Jin 2019). The success of a mega sports event depends on resources from a variety of its stakeholders, for example, participating (star) athletes, local hosts and venues, security, broadcasters and media, sponsors. Media, host organizations and the host city are critical stakeholders in festival brand management (Getz \& Fairley 2004). The interaction among these stakeholders is critical to event or destination branding, in which all parties share an interest in the outcome of an enhanced destination or event brand (Getz \& Fairley 2004). 
There are discussions as to whether events (e.g., festivals) can be managed as brands and research indicates that festival branding could occur in an ad hoc manner, with host organizations leading the branding process and sponsors and host cities involved in the branding process (Mossberg \& Getz 2006). However, little is known on how event brand is created or co-created by different stakeholders, particularly in the social media space.

\section{Social media communication and retweet practices}

Social media marketing combines social media with other communication channels in creating value for stakeholders to achieve organizational goals, which covers four aspects, scope, culture, structure/hierarchies of networks, and governance (Felix, Rauschnabel, \& Hinsch 2017). Social media create user interactivity and could have a hierarchical structure to networks, resulting in fragmented, decentralised, dissolved, and cross-functional control of social media communication (Felix, Rauschnabel, \& Hinsch 2017). Current literature on social media marketing in the tourism and hospitality sector has confirmed the impact and role of social media in travel-related decision-makings (Leung, Law, van Hoof, \& Buhalis 2013). Events have a more complex network structure of stakeholders compared to the tourism and hospitality sector. This complexity implies the necessity of using social media as a more interactive platform for marketing and communication. Given the scarcity of studies in the field, it is worthwhile to investigate how events are communicated on social media and how the stakeholder network impacts on communication.

One of the important features of social media communication is reposting (retweeting in the case of twitter). Retweeting is not simply about reposting others' tweet but rather an act of contributing to "a conversational ecology in which conversations are composed of a public interplay of voices that give rise to an emotional sense of shared conversational context." (Boyd, Golder, \& Lotan 2010, p. 1). The power of retweeting particularly lies in its 
widespread and far-reaching effect of information diffusion, even the users are not directly participating, as "the stream of messages [through retweeting] allows individuals to be peripherally aware without directly participating" (Boyd, Golder, \& Lotan 2010 p. 1). As such, the analysis of retweeting can offer insights into how twitter users have interaction with each other through various information types and subsequently, gain deeper knowledge on "ways in which modern human interactions get organized in the form of online networks, and contextualized” (Majmundar, Allem, Cruz, \& Unger 2018, p. 2). Studies of retweeting have flourished in various contexts including marketing message diffusion, controversial debate, bird flu information and crisis management and have examined the retweeting network structure, the motivation of retweeting, and retweet typology. Majmundar et al (2018) shows that the motivations of retweeting are to show approval, argue, gain attention, and entertain. By studying the marketing message diffusion through e-cigarette's retweeting practices, Chu et al. (2015) show that brands should target important gatekeepers and hubs so that message diffusion can be examined. However, while these studies offer insights into the retweeting practices, less is known in the events context. More importantly, empirical studies are limited in theorizing such practices.

\section{Social Network Analysis approach}

Social network theory provides a framework for analyzing stakeholder interactions for organization success. A network is a set of actors connected by a set of ties, which can be either directed or undirected, dichotomous or valued (Borgatti \& Foster 2003). SNA identifies the interdependence of actors to reveal the opportunities, constraints, and behaviours inherent with their positions in the network (Wasserman \& Faust 1994). Examining the networks help organizations identify the sources of influence, power, 
competitive advantage, opportunities and threats from the environment (Ter Wal \& Boschma 2009).

Studies employing SNA have been prolific in sociology, medicine, psychology, and information science (Otte \& Rousseau 2002). Many studies focus on the structure of interconnection. The structural approach focuses mainly on the number of connections and position of an actor in the network (Burt 1992). Properties in the network consist of centrality, position, strength of ties, cohesion, and division (White 1997). Centrality is the position of an actor. Betweenness measures centrality, and a high degree of betweenness indicates a mediator role of an actor/ a node. Actors in the most central positions have the shortest aggregate distances to all other actors and can reach other actors through a minimal number of intermediary positions. These actors are brokers and gatekeepers (Scott 1991). Density measures the level of connectivity and influences degree of resistance to stakeholder demands (Oliver 1991). High density makes communication across the network more efficient. The denser and larger a user's portfolio of relationships is, and the more central its position of the portfolio, the more likely that user is to be an influencer in their network. Thus, organizations with centrality in a dense network can have multiple advantages in the flow of information, support, and resource acquisition, while those at the periphery, with few links, might very well be permanently disadvantaged (Otte \& Rousseau 2002).

Some studies have examined how networks change over time. Preferential attachment, homophily and triadic closure are deemed as three forces that shape the temporal and spatial evolution of networks (Ter Wal \& Boschma 2009). As a result of preferential attachment, nodes in focal positions will become more central, whereas peripheral nodes may remain peripheral, resulting in a high degree of core-periphery structures (Orsenigo et al 1998). Because choice of links could be biased towards actors that are similar, a network could be 
formed and based on homophily (McPherson, Smith-Lovin, \& Cook 2001), which could be either caused by geographical, social, or cognitive proximity (Ter Wal \& Boschma 2009). Geographical closeness drives homophily, for example, Twitter users who have fewer than 2,000 reciprocal relations are likely to be geographically close (Kwak, Lee, Park, \& Moon 2010). Online homophily could be driven by social or cognitive proximity, evident in shared group interests and group mind-set (Brown, Broderick \& Lee 2007). Source credibility in an online environment plays a role, which could be verified by 'site trustworthiness' and 'actors' expertise' (Brown, Broderick \& Lee 2007). A third force in shaping the structural change over time is triadic closure, in which partners of partners become partners among themselves, producing cliques of strongly interconnected users/actors (Skvoretz 1999). Yet, few studies have tested the effects of the three forces on the temporal and spatial change of networks.

In summary, despite SNA is abundantly employed and generates considerable theoretical insights, there remains an intriguing gap in the event literature concerning the relationship ties of events stakeholder groups and its wide implications. Studies categorise stakeholder groups in a slightly different manner to that of manufacturing firms, although agree that these stakeholders could be classified according to its criticality to the success of events (Getz \& Fairley 2004). Twitter is a widely used network platform to disperse information, which is distinct from other network platform in its extraordinary number of additional recipients not affected by the number of followers of the original post (Kwak et al 2010). This is especially true in the events context due to the multi-stakeholder structure, and thus, an examination of the social media communication of a mega event via examining the tweet-retweet structure of the event stakeholders will help advance understandings and theories in both social media communication and the network approach. 


\section{Methods}

The research setting

This paper uses the 2018 Commonwealth Games (GC2018) as a case to examine social media communication in the events context. Held every four years, the Commonwealth Games are a well-known, international, mega sport event. Different from the Olympic Games or FIFA, the Commonwealth Games carries a legacy and tradition that is distinctively British, involving athletes only from the Commonwealth of Nations, but also attracting media or viewer attention from non-Commonwealth Nations. Recent Games were hosted in Deli, India, (2010), Glasgow (2014) and Gold Coast (2018). City of Gold Coast, Australia, won the bid for hosting the 2018 Commonwealth Games in 2011. The city of Durban, South Africa, originally won the 2022 Commonwealth Games in 2015 but was stripped the right to host in March 2017 due to financial issues. Birmingham (UK), Liverpool (UK) and Victoria (Canada) participated in the $2^{\text {nd }}$ election, and in December 2017 Birmingham won the bid. Characteristics such as the complexity of the stakeholder relationships and impact of the Games on tourism of the host locations make the Commonwealth Games an interesting setting for a study on event social media communication by its multiple stakeholders.

\section{Rationale for using Twitter Data}

Twitter is chosen as it is one of the most widely used social media marketing site; approximately $73 \%$ of Fortune 500 companies use it for marketing and communication purposes (Whitelock, Cadogan, Okazaki, \& Taylor 2013). Twitter is characterised as being short, speedy, numerous conversations. Twitter's mechanism (e.g., retweet and \#hash tag) encourages conversations and sharing, which could potentially build up a relationship among users and spread information of their choice beyond the reach of the original user's followers (Kwak, Lee, Park \& Moon 2010). The average information flow on Twitter could be less than 
5 degree of separation between $90 \%$ user pairs (Kwak et al 2010). Twitter has an asymmetrical follower model - marketers (Twitter users) and their followers do not need to give mutual approval to follow or become followers. Thus, it is convenient for marketers to interact with interested customers on Twitter, as well as collect real-time market insights, intelligence, and feedback. Public tweets are also available for anyone to read, whether logged into Twitter or not. Thus, Twitter, as an open and public communication conduit, could help marketers to spread their messages to a greater audience, beyond followers (Swani, Brown, Milne 2014). The rate and direction of change in a social media conversation (Kietzmann et al 2011) can inform organizations of the effectiveness of their marketing mix. Thus, an analysis of tweet-retweet structure could provide insights into marketing and communication of a mega event by its various stakeholders.

The number of followers a marketer (Twitter user) has on Twitter could be an indication of the popularity of that account, but it is not an exact indication of how many people read the tweets. Thus, examining the number of times the marketer is mentioned in other tweets, the number of their messages being retweeted, how often other users (with or without connections) mention the marketer, and the geographical reach of other users would generate more accurate understanding of the effectiveness of the marketing and branding effort by the marketer using Twitter. This is the gap this research aims to fill by examining the social network structure of twitter users in mega events.

\section{Data collection and analysis}

In order to understand the social network structure of the key stakeholders of the Commonwealth Games and the change of the network overtime, two periods of twitter data were obtained and used in the analysis. We used Python (packages used include Scrapy, Selenium, lxml, and requests) to crawl the tweets (using the hashtag "Commonwealth 
Games" and the key term - Commonwealth Games as the search enquiry) in two time periods. We harvested a total of 3,644 tweets in the first time period spanning from May 23 to July 23, 2017 and 3,348 tweets in the second time period spanning from April 4 to 14, 2018. The first time period was about 9 months before the 2018 Commonwealth Games started. The second time period was during the game time. For both time periods, key information was retrieved from Tweets, including content of tweets, who posted the tweets, type of tweets (tweet or retweet), time of posting, posting users' short bios, and geographical location of tweets. The information is saved in excel files for data analysis.

SNA was performed to map out the connections between contributors based on the tweet and retweet structure on Twitter. Degree represents the number of ties between nodes and actors. Betweenness centrality was used to identify the user' centrality in the network by calculating its number of shortest paths as the users with higher betweenness centrality scores would have more control over the network in terms of its information flow (Brandes, 2001).

In addition, the Louvain method was used to detect communities by identifying the common network structure within a community. The rationale in using the Louvain method (Blondel, Guillaume, Lambiotte, \& Lefebvre 2008) is that it works fast for large networks and provides excellent accuracy (Liu, Glänzel, \& Moor 2012) by measuring the meaningfulness of network division into communities. In the network graph visualized by Gephi, the size of the bubble/dots presents the normalised connections received by the contributors and the size of the thickness of the lines represents the strength of connections ties. The communities identified are color-coded - dots in the same colour mean they are in the same communities.

To better understand and visualise key stakeholders and their positions in the network, such as which stakeholder groups are active in Twitter and with which other groups they connect, we identify and categorise stakeholders into eight categories and use a number to label each 
category (see Table 1). These categories are the governing bodies, the planning and implementing bodies, game allies and collaborators, bodies with an interest in the game outcomes (e.g., sport associations), bodies with an interest in game outcomes (e.g., businesses), participating individuals (e.g., athletes, officials, volunteers and spectators), media, and the impacted individuals (e.g., not-participating local residents). The same number label (1-8) is used when reporting the main contributors to the Twitter communication (see Table 2), which clearly indicates stakeholder groups that are active or inactive in the social media space. 
Table 1 - Stakeholder framework of the Commonwealth Games

\begin{tabular}{|c|c|c|c|c|c|c|c|}
\hline $\begin{array}{l}\text { Games governing } \\
\text { bodies (1) }\end{array}$ & $\begin{array}{l}\text { Games planning } \\
\text { and implementing } \\
\text { bodies (2) }\end{array}$ & $\begin{array}{l}\text { Games allies and } \\
\text { collaborators (3) }\end{array}$ & $\begin{array}{l}\text { Bodies with an } \\
\text { interest in the } \\
\text { outcomes of the } \\
\text { Games (sport } \\
\text { associations) (4) }\end{array}$ & $\begin{array}{l}\text { Bodies with an } \\
\text { interest in the } \\
\text { outcomes of the } \\
\text { Games } \\
\text { (businesses) (5) }\end{array}$ & $\begin{array}{l}\text { Games } \\
\text { participating } \\
\text { bodies/Bodies } \\
\text { with an interest in } \\
\text { the outcomes of } \\
\text { the Games } \\
\text { (individuals) (6) }\end{array}$ & Media (7) & $\begin{array}{l}\text { The impacted } \\
\text { (individuals) - (8) }\end{array}$ \\
\hline $\begin{array}{ll}\text { - } & \text { The } \\
\text { Commonweal } \\
\text { th Games } \\
\text { Federation } \\
\text { (CGF) } \\
\text { - International } \\
\text { Sports } \\
\text { Federations } \\
\text { - Commonweal } \\
\text { th Games } \\
\text { Associations }\end{array}$ & $\begin{array}{ll}\text { Games } \\
\text { Organising } \\
\text { Committee } \\
\text { (e.g. Gold } \\
\text { Coast } 2018 \\
\text { organising } \\
\text { committee } \\
\text { GOLDOC) } \\
\text { Local } \\
\text { government } \\
\text { (e.g., } \\
\text { Queensland } \\
\text { Government) } \\
\text { Local city } \\
\text { council (e.g., } \\
\text { City of Gold } \\
\text { Coast) }\end{array}$ & $\begin{array}{ll}\text { - } & \text { Tourist } \\
\text { Bureau/DMO } \\
\text { s (e.g., } \\
\text { Tourism \& } \\
\text { Events } \\
\text { Queensland, } \\
\text { Gold Coast } \\
\text { Tourism) } \\
\text { - Sponsors and } \\
\text { partnerships } \\
\text { - Co-producers } \\
\text { of the Games, } \\
\text { e.g., staging } \\
\text { companies, } \\
\text { venues }\end{array}$ & $\begin{array}{ll}\text { Local sports } \\
\text { associations } \\
\text { (e.g., } \\
\text { Australia } \\
\text { Commonweal } \\
\text { th Games } \\
\text { Association, } \\
\text { Boxing } \\
\text { Australia, } \\
\text { Athletics } \\
\text { Australia) } \\
\text { - International } \\
\text { bodies/associa } \\
\text { tions (e.g., } \\
\text { Team } \\
\text { Scotland) }\end{array}$ & $\begin{array}{ll}\text { - } & \text { Local tourism } \\
\text { businesses } \\
\text { (e.g., } \\
\text { accommodati } \\
\text { on, hospitality } \\
\text { and catering, } \\
\text { leisure and } \\
\text { entertainment, } \\
\text { transportation } \\
\text { ) } \\
\text { Other local } \\
\text { supporting } \\
\text { industries } \\
\text { (e.g., DMCs, } \\
\text { retail) }\end{array}$ & $\begin{array}{ll}\text { - } & \text { Athletes } \\
\text { - } & \text { Game } \\
& \text { officials } \\
\text { - } & \text { Employees } \\
\text { - } & \text { volunteers } \\
\text { - } & \text { Sports fans } \\
\text { - } & \text { Visitors/spect } \\
& \text { ators }\end{array}$ & $\begin{array}{ll} & \text { Media (e.g., } \\
\text { TV channels } \\
\text { with or } \\
\text { without } \\
\text { broadcasting } \\
\text { rights, } \\
\text { newspapers, } \\
\text { other media) }\end{array}$ & $\begin{array}{ll}\text { - } & \text { Non- } \\
& \text { participating } \\
& \text { visitors } \\
\text { - } & \text { Residents } \\
\text { - } & \text { Others }\end{array}$ \\
\hline
\end{tabular}




\section{Findings}

Active contributors/actors on Twitter in communicating CWG

In the pre-game data, there were 1,414 tweets and 2,230 retweets, posted by 2,237 unique users. In the during-game dataset, 3,347 tweets were obtained posted by 1,320 unique users. Table 2 reports top 20 Twitter users who posted a greater number of tweets in the two study periods. This result helps identify the most active users in the twitter network, and the stakeholder clusters that they belong to. Findings indicate that, in both periods, media and especially sports media (label number 7 in Table 1 and Table 2 under stakeholder type) were the most visible and active contributors to the conversation of GC2018 on Twitter. Media from the UK, Australia and India were the most active ones in both periods, whereas media from other commonwealth countries (e.g., South Africa or Canada) became active only during the game time. The second most active group was sports associations (label number 4). In the pre-game dataset, five sports associations occurred on the top 20 list and all of them were from the UK. In the during-game dataset, eight sports associations emerged on the list, including associations from the Great Britain, Scotland, India, New Zealand). But, interestingly, no sport associations from Australia seemed to be sufficiently active on Twitter. The game governing body (label number 1) -i.e, Commonwealth Games Federation (thecgf) and CommGamesAUS, as well as the planning and implementing body (label number 2) i.e., GC2018, performed their duties in publicising the upcoming games, with both appeared at the bottom of the top 20 list. Individual accounts (label number 6), especially the official accounts of VIPs, played a role in the twitter conversation of GC2018. These accounts included the accounts of the head of the organising committee, the premier of Queensland, the President of India, the Prince of Wales, and several famous current or retired elite athletes. Mysteriously, in the pre-game dataset, several individuals (or individual firms) who may not have direct connections to GC2018 appeared to be among the most active 
contributors to posts concerning GC2018. For example, Fallout contributed the greatest number of tweets and formed a biggest bubble, but this user had little to do with sports or the commonwealth games. A scrutiny of their tweets indicated that these users maybe utilising the sport context (the Games or the cities bidding for the next Games) to promote their own products or personal profiles. Two key stakeholder groups, namely the local government (label number 2) and the DMOs (label number 3), were missing on the list. Except Visit Birmingham (i.e., DMO) emerged on the list in the pre-game dataset, no other local tourism bureaus appeared to be very active in the Twitter communication of GC2018.

\section{Network of the active contributors/actors in twitter}

Network analysis was conducted for both periods based on retweet network. In the pre-game dataset, the network analysis revealed 236 communities, indicating a loose network structure. The top 5 largest communities were respectively $10.2 \%, 8.99 \%, 7.2 \%, 5.35 \%$, and $4.25 \%$ based on their modularity scores (modularity score $=0.937$ ). Figures 1.1 to 1.3 are visual representations of the distribution of the communities and users. The two large communities were users located respectively in the UK and Australia. In the during-game dataset, the network analysis identified 97 communities, indicating a dense network structure. The top 5 largest communities were respectively $9.63 \%, 7.11 \%, 6.75 \%, 5.92 \%$, and $5.69 \%$ based on their modularity scores (modularity score $=0.839$ ). Pictures in Figures 2.1 to 2.7 are visual representations of the network and distribution of the communities and users. Appendix 1 is a full-size network of the data in the period which could be zoomed in and out for a clear view of the network and contributors. 
Table 2 Active Users by Number of Tweets Distribution Per User

\begin{tabular}{|c|c|c|c|c|c|}
\hline $\begin{array}{l}\text { Dataset } 1 \text { - Pre-Game Period (May } 23 \\
\text { to July } 23,2017 \text { ) } \\
\text { User Name }\end{array}$ & $\begin{array}{l}\text { Stake } \\
\text { holder } \\
\text { Type }\end{array}$ & $\begin{array}{l}\text { No of } \\
\text { Tweets }\end{array}$ & $\begin{array}{l}\text { Dataset } 2 \text { - During Game Period (April } 4 \\
\text { to April 16, 2018) } \\
\text { User name }\end{array}$ & $\begin{array}{l}\text { Stake } \\
\text { holder } \\
\text { Type }\end{array}$ & $\begin{array}{l}\text { No of } \\
\text { Tweets }\end{array}$ \\
\hline Fallout (a Vault-Tec corporation) & 8 & 214 & BBCSport & 7 & 178 \\
\hline Liverpool Echo (news agency) & 7 & 97 & SuperSportTV (South Africa) & 7 & 65 \\
\hline Prof Brian Spurtice (no geo-location) & 8 & 92 & Team_Scotland & 4 & 63 \\
\hline Team Scotland & 4 & 70 & 7CommGames & 7 & 50 \\
\hline Nine News Gold Coast & 7 & 60 & $\begin{array}{l}\text { PMOIndia (Office of the Prime Minister } \\
\text { of India) }\end{array}$ & 7 & 47 \\
\hline University of Birmingham & 5 & 50 & $\begin{array}{l}\text { DDNewsLive (Public Broadcaster of } \\
\text { India) }\end{array}$ & 7 & 46 \\
\hline $\begin{array}{l}\text { Liverpool FC (Liverpool Football } \\
\text { Club) }\end{array}$ & 4 & 49 & TeamGB & 4 & 43 \\
\hline Welsh Rugby Union & 4 & 47 & $\begin{array}{l}\text { DDNational (Doordarshan National } \\
\text { channel, India) }\end{array}$ & 7 & 41 \\
\hline 7 News Queensland & 7 & 45 & $\begin{array}{l}\text { ddsportschannel (India's Public Service } \\
\text { Broadcaster) }\end{array}$ & 7 & 36 \\
\hline Joe Scarry (Adovacate) & 8 & 44 & TeamEngland & 4 & 35 \\
\hline BBC Sport & 7 & 43 & BBCSportWales & 7 & 34 \\
\hline 7 News Gold Coast & 7 & 42 & $\begin{array}{l}\text { rashtrapatibhvn (Rashtrapati Bhavan, } \\
\text { President of India) }\end{array}$ & 6 & 30 \\
\hline BBC Merseyside & 7 & 38 & GC2018 (official account for GC2018) & 2 & 28 \\
\hline Birmingham Newsroom & 7 & 38 & $\begin{array}{l}\text { CBCOlympics (Canada's offical } \\
\text { broadcaster for Olympic Games) }\end{array}$ & 7 & 26 \\
\hline $\begin{array}{l}\text { Kirralie Smith (Adovacate and } \\
\text { Entrepreneur) }\end{array}$ & 8 & 38 & $\begin{array}{l}\text { Ioaindia (Team India, Indian Olympic } \\
\text { Association) }\end{array}$ & 4 & 26 \\
\hline Jas Sansi (Photographer) & 8 & 36 & CommGamesAUS & 1 & 25 \\
\hline $\begin{array}{l}\text { Everton (Everton Football Club, } \\
\text { Liverpool) }\end{array}$ & 4 & 31 & $\begin{array}{l}\text { SirJadeja (Sir Ravindra Jadeja, Indian } \\
\text { cricketer) }\end{array}$ & 6 & 24 \\
\hline $\begin{array}{l}\text { BJP LIVE (Internet TV by a Party in } \\
\text { India) }\end{array}$ & 7 & 25 & Airnewsalerts (India Radio News) & 7 & 22 \\
\hline British Swimming & 4 & 25 & $\begin{array}{l}\text { TeamSA18 (South Africa Sports } \\
\text { Confederation \& Olympic Committee) }\end{array}$ & 4 & 22 \\
\hline $\begin{array}{l}\text { TIMES NOW (India's most watched } \\
\text { English news channel) }\end{array}$ & 7 & 24 & India_AllSports & 7 & 21 \\
\hline Birmingham Mail & 7 & 22 & $\begin{array}{l}\text { Ra_THORe (Indian politician and } \\
\text { former Olympian) }\end{array}$ & 6 & 21 \\
\hline $\begin{array}{l}\text { GC2018 (official account for } \\
\text { GC2018) }\end{array}$ & 2 & 22 & Britishswimming & 4 & 20 \\
\hline $\begin{array}{l}\text { Matchroom Boxing (UK boxing } \\
\text { promoter) }\end{array}$ & 4 & 22 & $\begin{array}{l}\text { JagratiShukla29 (co-founder of Alt } \\
\text { News, India) }\end{array}$ & 7 & 18 \\
\hline PIB India (Press Information Bureau) & 7 & 21 & ndtv (India sportTV) & 7 & 18 \\
\hline Liverpool Now & 7 & 20 & $\begin{array}{l}\text { Virenrasquinha (Former Captain of the } \\
\text { Indian Hockey Team) }\end{array}$ & 6 & 18 \\
\hline $\begin{array}{l}\text { Molly Caudery (International pole- } \\
\text { vaulter | Cornwall) }\end{array}$ & 8 & 20 & $\begin{array}{l}\text { ClarenceHouse (Account of The Prince } \\
\text { of Wales) }\end{array}$ & 6 & 17 \\
\hline Peter Beattie (GOLDOC CEO) & 6 & 20 & Nzolympics (NZ Olympic Team) & 4 & 17 \\
\hline \multirow[t]{2}{*}{ Visit Birmingham } & 5 & 20 & AthleticsCanada & 4 & 16 \\
\hline & & & $\begin{array}{l}\text { Thecgf (Commonwealth Games } \\
\text { Federation) }\end{array}$ & 1 & 16 \\
\hline
\end{tabular}

\footnotetext{
* Tweets that only contain the search terms "commonwealth games".
} 
To further identify the network values of each user, we filtered the network with nodes (with average degree scores being at least 5). Network structures in both time periods are visually presented in Figures 1 and 2. The results indicate that the networks were mainly composed of accounts of organizations rather than accounts of individuals, showcasing that key actors were mainly organizations.

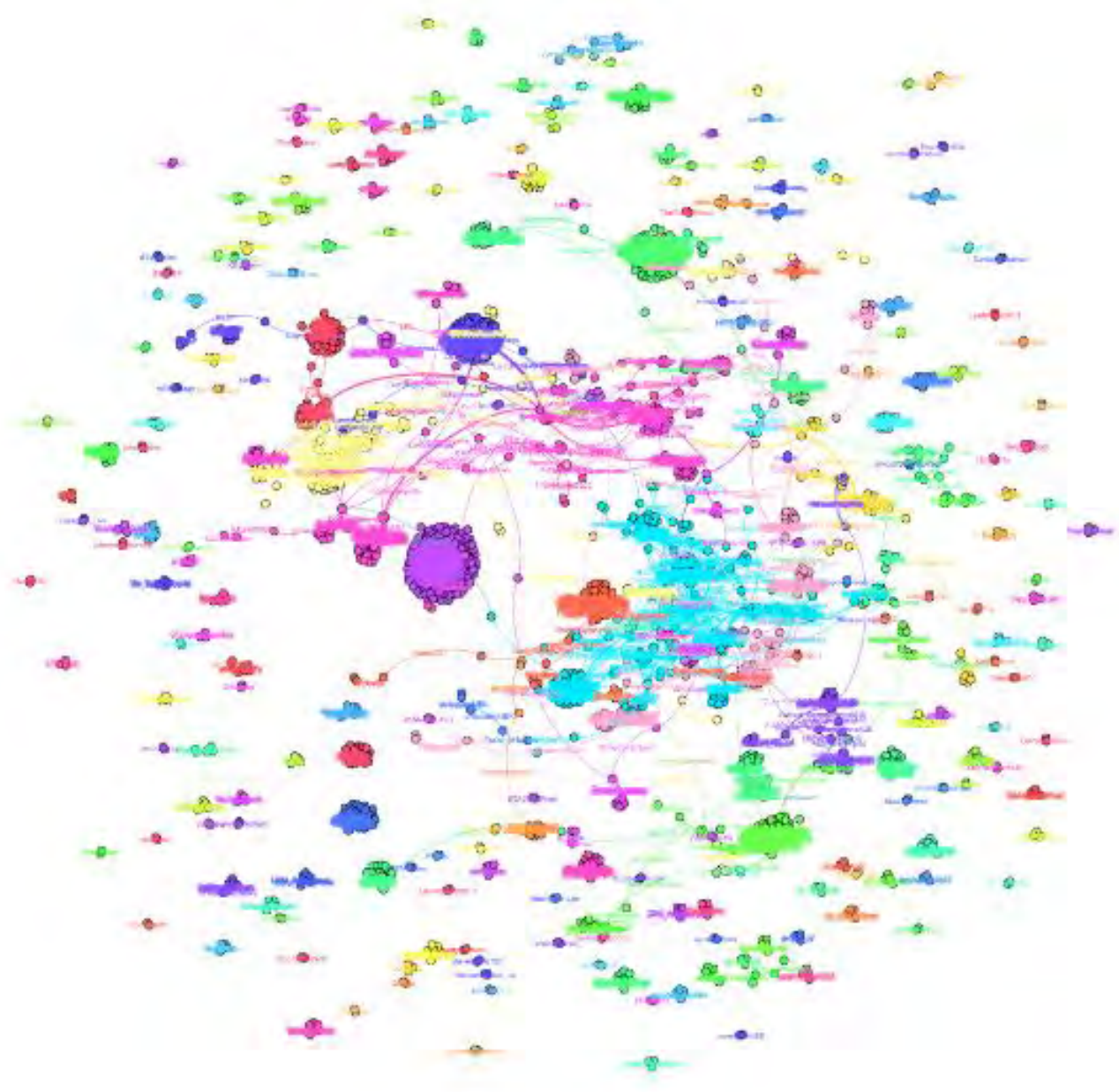

Figure 1.1 Pre-Game Period (May to July 2017) Overall User Network 
MENrefsosk

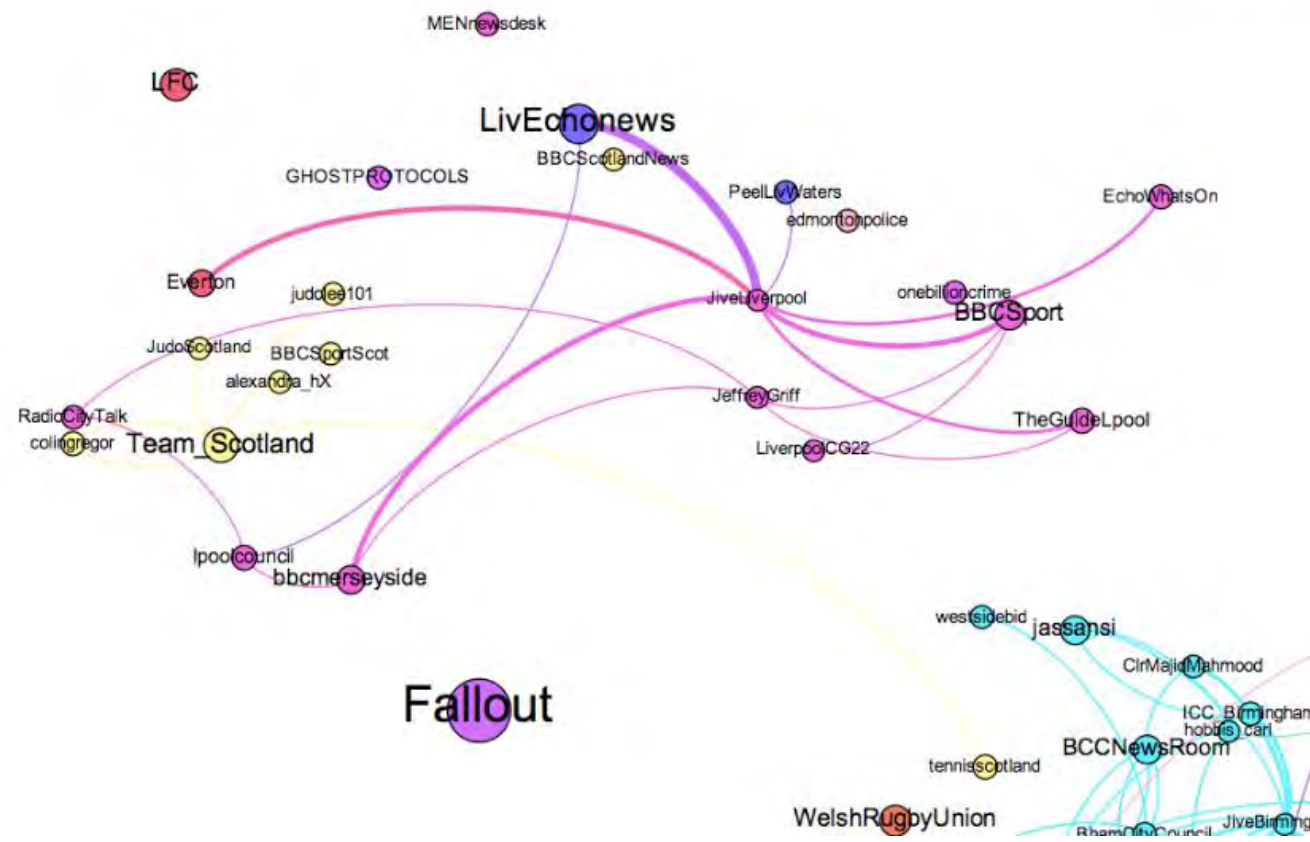

Figure 1.2 Pre-Game Period (May to July 2017) UK User Network

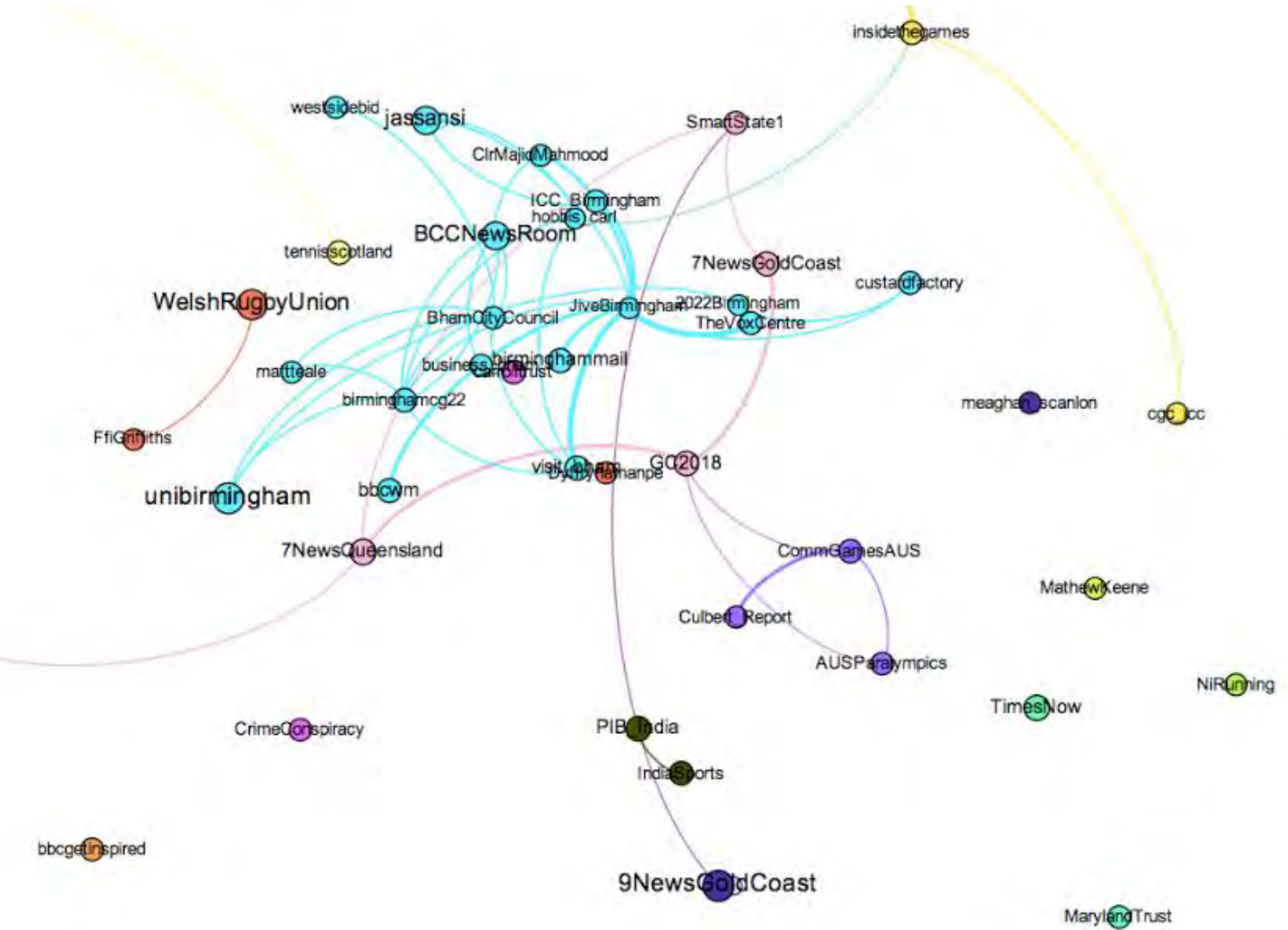

Figure 1.3 Pre-Game Period (May to July 2017) Australia User Network 
Tweets posted by these organizations were further examined to find a logical link to the dominant communities. In the pre-game dataset, five major communities were identified. The first group consisted of agencies located in Liverpool and Birmingham and the tweets were mostly about the bidding for the next Commonwealth Games (and at least Birmingham won the bid - see brief on the Games in the prior text). The second group was centred on BCCNews Room, which endorsed Liverpool but also highlighted that it would be good for the UK to host the 2022 Commonwealth Games. The third group was Gold Coast based agencies promoting various key messages from a local perspective including the games' role with indigenous communities, ticket sales, popular sessions, host and organizations' efforts and safety. However, these messages tended to travel within the Gold Coast communities. Despite Gold Coast being the host city of the forthcoming games, agencies from the Gold Coast were at the peripheral level of the network. Their influence in spreading information in the network was not apparent. There were many individual twitter users, even though they were active in posting, they spread their information widely within their own communities, resulting in the formation of their own cliques. One of these cliques was the fallout, which was irrelevant to sports or The Commonwealth Games and had no influence on other communities in the network. The communities in this period were connected primarily by geographic proximity and occasionally by homophily. 


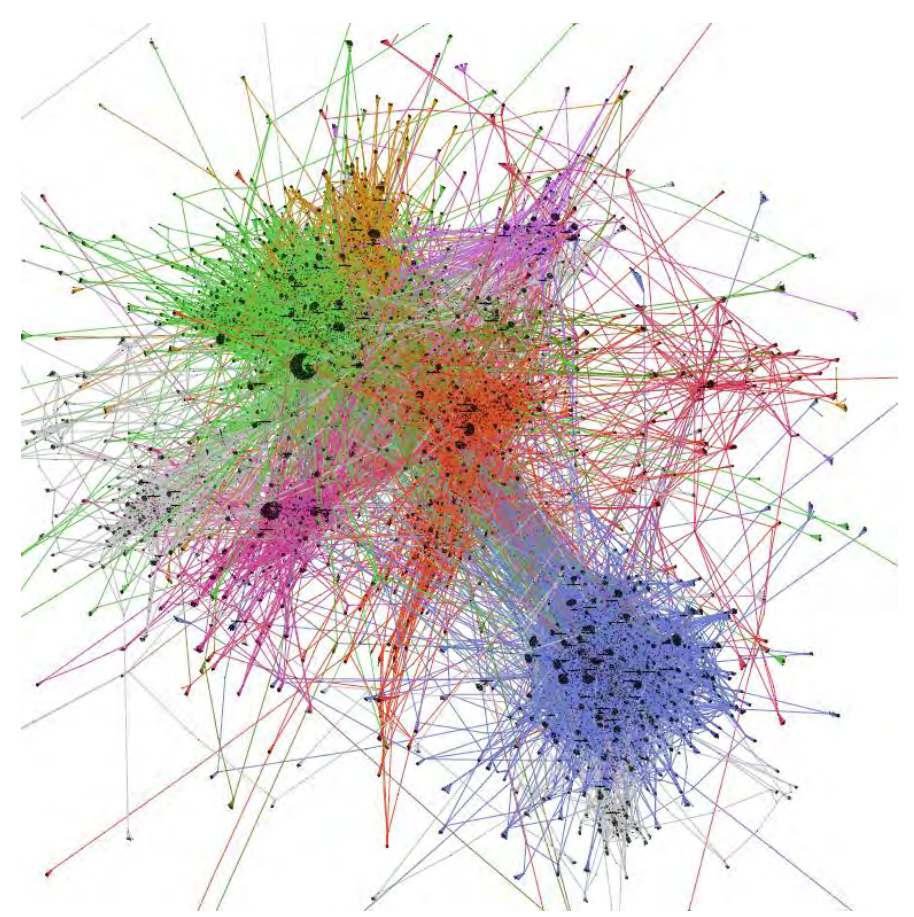

Figure 2.1 April 2018 During Game Period Overall User Network

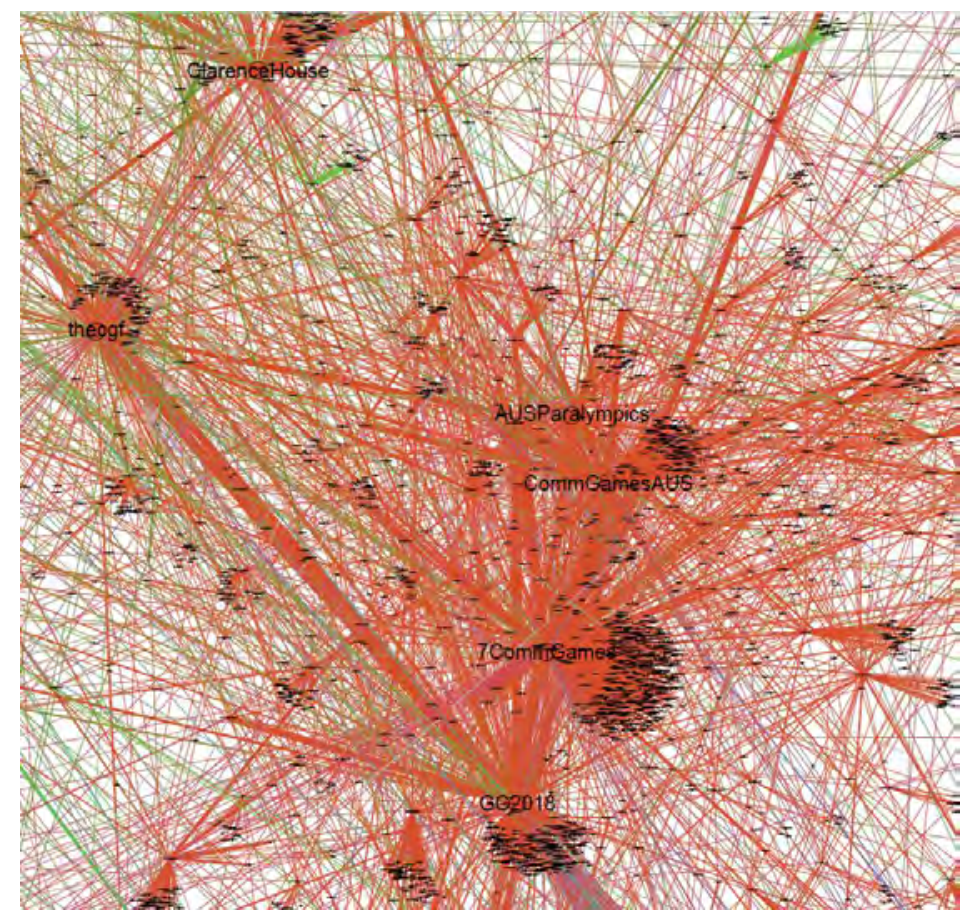

Figure 2.2 April 2018 During Game Period Australia User Network 


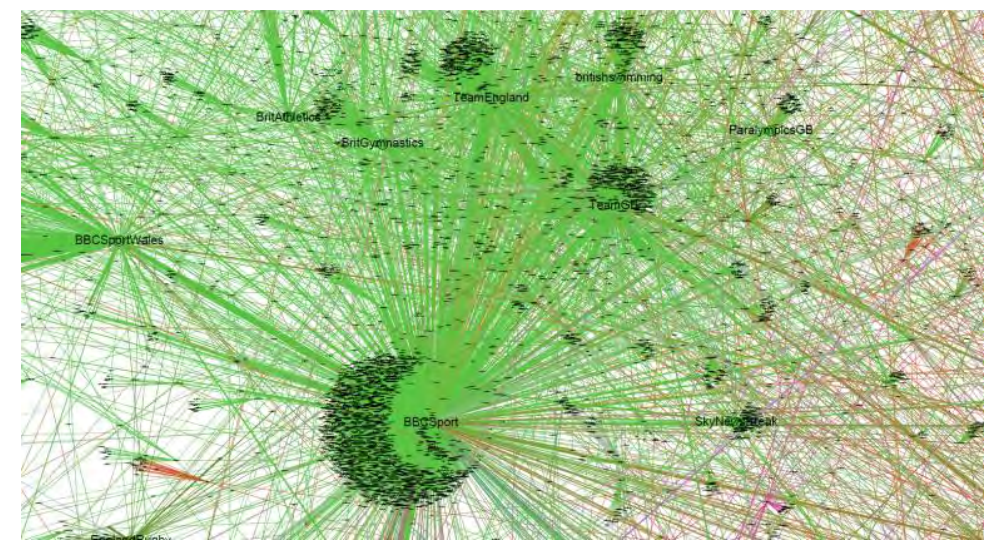

Figure 2.3 April 2018 During Game Period UK User Network

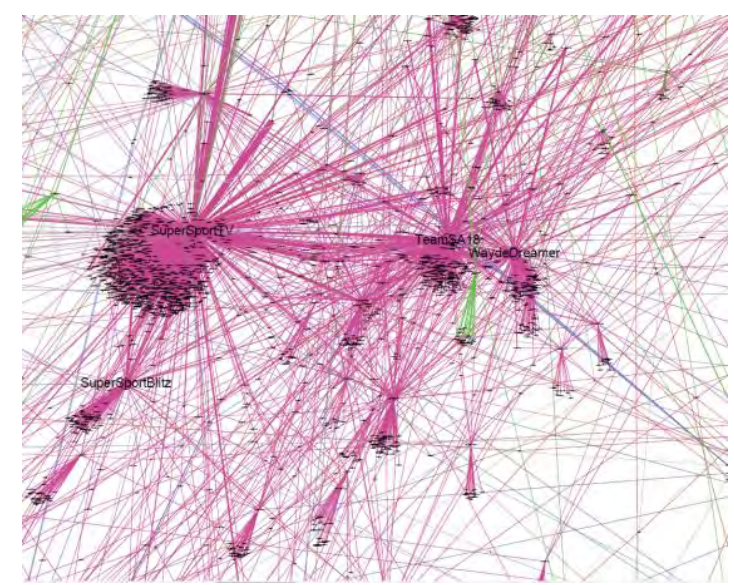

Figure 2.4 April 2018 During Game Period South Africa User Network

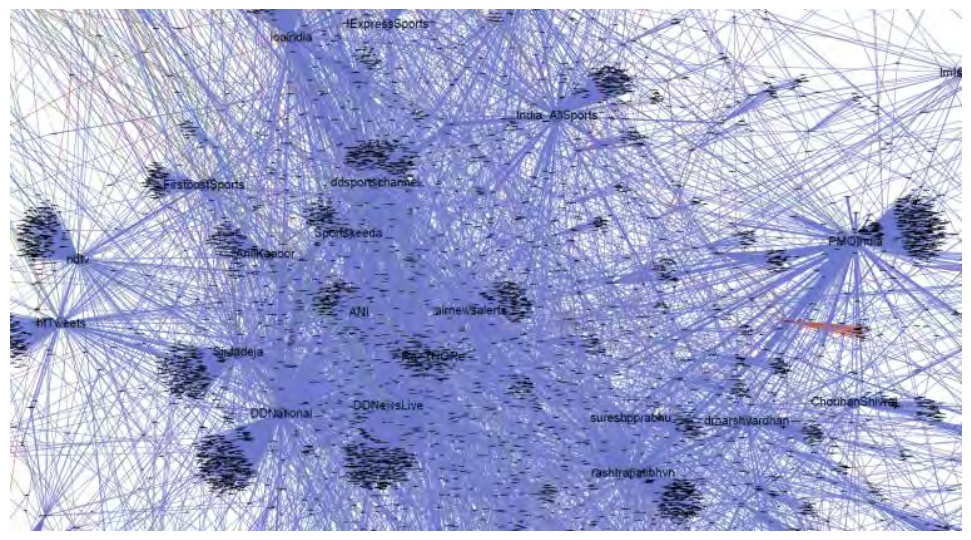

Figure 2.5 April 2018 During Game Period India User Network 


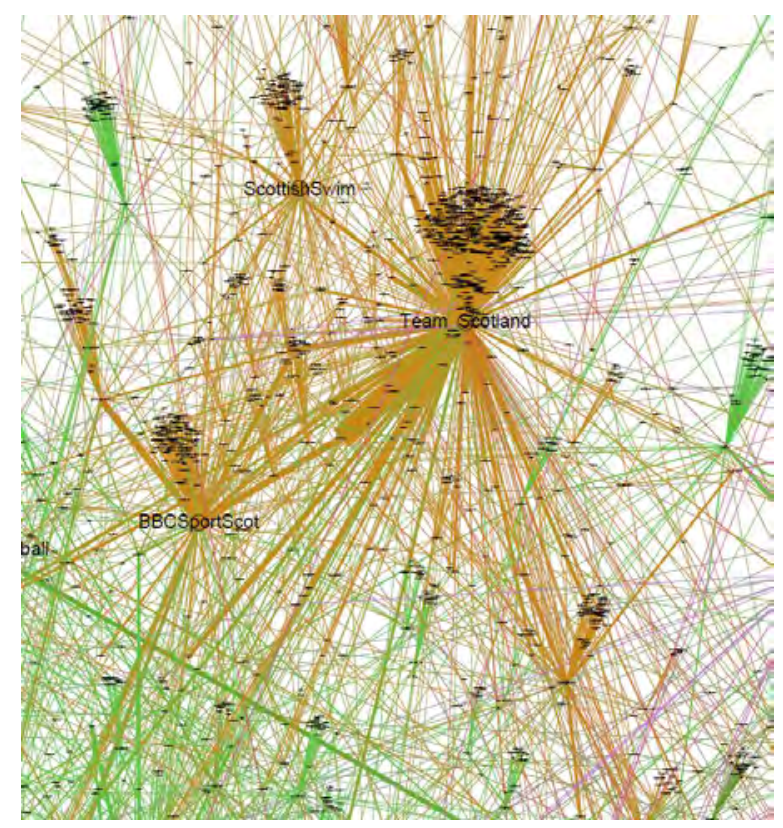

Figure 2.6 April 2018 During Game Period Scotland User Network

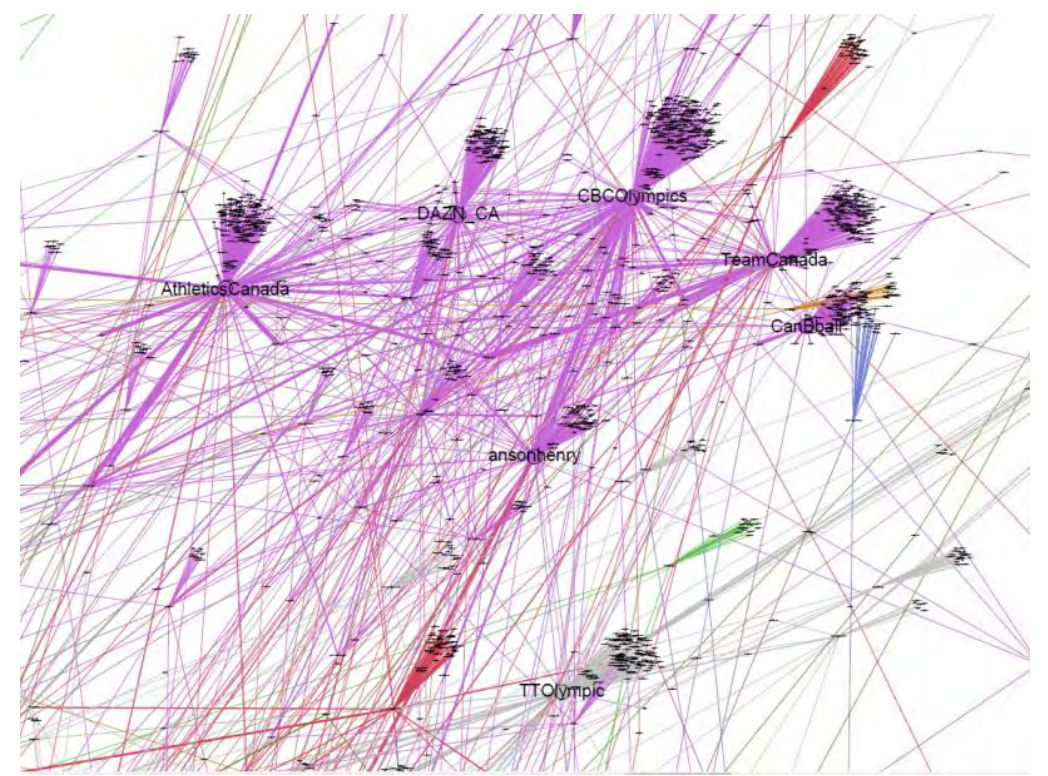

Figure 2.7 April 2018 During Game Period Canada Twitter User Network Note: the communities are color-coded, which are largely geographically linked users, as green clusters are mostly users from the UK, grey from Africa, yellow from Scotland, red (in the central position) from Australia. 
The during-game dataset revealed six distinct communities, and again, a closer examination of the bios of the users indicates that the communities clustered together mainly due to their geographical connections (Figures 2.1-2.7). The large color-coded clusters respectively represent users based in the UK (green, upper left), Australia (red, middle), India (blue, down right), Scotland (yellow, upper left), Africa (grey, down left), Canada (purple, upper middle). Within Australia, 7CommGames, GC2018, CommGamesAUS were in the central positions (these accounts also had a greater number of tweets). AUSParalympics almost merged with CommGamesAUS; this probably was a result of the active participation of Paralympics in this event because this was the first time a mega sport event included athletes with disabilities as full members of their national teams and their medals were included in the medal count. Thecgf (i.e., Commonwealth Games Federation) and ClarenceHouse (Account of The Prince of Wales) were on the verge of the red cluster and acted as intermediaries between the AU and the UK communities. The communities in this period were connected almost entirely by geographic proximity and a few key actors took the central positions to connect between geographically-based clusters.

Network structure: User centrality and change over time

The network structures (Figures 1.1-1.3 and 2.1-2.7) derived from the network analysis highlights some key findings. First, users with the highest betweenness centrality score might not be the most active users with a greater number of original tweets, although there were a few actors that emerged on both lists (Tables 2 and 3). In the pre-game dataset, the accounts that were both active in posting and acted as intermediaries connecting different communities and users were LivEchonews (news agency), 7NewsGoldCoast, Team-Scotland, 9NewsGoldCoast, GC2018, BBCSport, and Everton (Football Club, Liverpool). These users were either media or sports media, although GC2018, the official organiser of the 
forthcoming game at the time, emerged in the middle of the list. Noticeably, the accounts that played a central role in the network had changed during the game time. In the during-game dataset, accounts who topped the list were BBCSport, GC2018, 7CommGames, TeamScotland, thecgf (Commonwealth Games Federation), TeamEngland, and CommGamesAUS. Information flow across the clusters was highly dependent upon these key intermediaries, which were mostly the game governing bodies (e.g., GC2018, CommGamesAUS, thecgf, 7GommGames), very large sports associations (Team-Scotland and TeamEngland), or sports media (BBCSport). Governing bodies played a key role as intermediaries for information flow among different clusters. Large media and sports associations played an important role for the flow of information across clusters and a key role within their own clusters. Local media (e.g., 9News and 7News in Australia) were key intermediaries for their own geographical community but became peripheral or external to other geographical clusters and were to be connected via the game governing bodies to users in other geographical regions. Celebrities or internet celebrities played a role in the information diffusion, especially accounts such as the President of India and MP of Queensland acted as key actors in the network. Some other active (influential) individuals in the network were star athletes or activists and the opinion of these influencers should be given due attention. Markedly, DMOs were nowhere on the list and their involvement could be described as minimal in this network. Sadly, media or sport media in the hosting county and location (i.e., the Gold Coast, Australia) did not rank high in the betweenness centrality list, implying that their power in information flow was largely refrained within their local followers. Spam accounts had disappeared over time. 
Table 3: Comparison of Betweenness Centrality - Pre vs During Game Time

\begin{tabular}{|c|c|c|c|c|}
\hline $\begin{array}{l}\text { Dataset } 1 \text { - Pre-Game } \\
\text { Period (May } 23 \text { to } \\
\text { July 23, 2017) } \\
\text { User Name }\end{array}$ & & $\begin{array}{l}\text { Dataset } 2 \text { - During } \\
\text { Game Period (April } \\
4 \text { to April 16, 2018) } \\
\text { User name }\end{array}$ & Pre-Event & During Event \\
\hline Id & $\begin{array}{l}\text { Betweenness- } \\
\text { centrality }\end{array}$ & Id & $\begin{array}{l}\text { Betweenness- } \\
\text { centrality }\end{array}$ & $\begin{array}{l}\text { Betweenness- } \\
\text { centrality }\end{array}$ \\
\hline $\begin{array}{l}\text { Insidethegames (UK } \\
\text { sport media) }\end{array}$ & 206858.2 & BBCSport & 56168.02 & 12946299 \\
\hline JiveLiverpool & 180289.7 & GC2018 & 58070.1 & 6984113 \\
\hline LivEchonews & 165180.1 & 7CommGames & $\# \mathrm{~N} / \mathrm{A}$ & 5158940 \\
\hline 7NewsGoldCoast & 150127.9 & Team_Scotland & 96988.4 & 3079547 \\
\hline guernseycga & 147815 & thecgf & $\# \mathrm{~N} / \mathrm{A}$ & 2232224 \\
\hline LMorgan21 & 106293.1 & TeamEngland & $\# \mathrm{~N} / \mathrm{A}$ & 2064968 \\
\hline Brandoath & 103130.6 & CommGamesAUS & 19662.9 & 1848642 \\
\hline Team_Scotland & 96988.4 & $\begin{array}{l}\text { miss_khamis } \\
\text { (Account is no } \\
\text { longer active. User } \\
\text { information can not } \\
\text { be identified) }\end{array}$ & $\# \mathrm{~N} / \mathrm{A}$ & 1644662 \\
\hline shewanlpool & 95647.94 & SuperSportTV & \#N/A & 1536747 \\
\hline BrianSpanner1 & 84465 & $\begin{array}{l}\text { Rashtrapatibhvn (the } \\
\text { President of India) }\end{array}$ & $\# \mathrm{~N} / \mathrm{A}$ & 1270936 \\
\hline SmartState1 & 75804.41 & DDNewsLive & $\# \mathrm{~N} / \mathrm{A}$ & 1210198 \\
\hline lpoolcouncil & 68295.89 & $\begin{array}{l}\text { Ddsportschannel } \\
\text { (India sports media) }\end{array}$ & $\# \mathrm{~N} / \mathrm{A}$ & 1201211 \\
\hline bbcmerseyside & 65640.25 & $\begin{array}{l}\text { Elizabethtoni } \\
\text { (broadcaster, } \\
\text { London) }\end{array}$ & $\# \mathrm{~N} / \mathrm{A}$ & 1187707 \\
\hline hobbis_carl & 65307.8 & $\begin{array}{l}\text { Vijay_Rules_Da } \\
\text { (sports fan) }\end{array}$ & $\# \mathrm{~N} / \mathrm{A}$ & 1140490 \\
\hline 9NewsGoldCoast & 62613.32 & $\begin{array}{l}\text { DDNational (India } \\
\text { media) }\end{array}$ & $\# \mathrm{~N} / \mathrm{A}$ & 1127821 \\
\hline JiveBirmingham & 58461.64 & BBCSportWales & $\# \mathrm{~N} / \mathrm{A}$ & 1073633 \\
\hline Duncan_ITG & 58267.81 & $\begin{array}{l}\text { AnnastaciaMP (MP } \\
\text { of Queensland) }\end{array}$ & $\# \mathrm{~N} / \mathrm{A}$ & 1027917 \\
\hline GC2018 & 58070.1 & TheHockeyIndia & $\# \mathrm{~N} / \mathrm{A}$ & 930169.3 \\
\hline BBCSport & 56168.02 & $\begin{array}{l}\text { QldPolice } \\
\text { (Queensland Police) }\end{array}$ & $\# \mathrm{~N} / \mathrm{A}$ & 832337.2 \\
\hline ICC_Birmingham & 51863.38 & TeamGB & \#N/A & 785294.2 \\
\hline Brummie_am_we & 49502.72 & $\begin{array}{l}\text { Laura_Ann_94 } \\
\text { (Entertainment } \\
\text { reporter, Australia) }\end{array}$ & 0 & 777628.1 \\
\hline Everton & 45725.11 & $\begin{array}{l}\text { AupolNews (News, } \\
\text { Australia) }\end{array}$ & $\# \mathrm{~N} / \mathrm{A}$ & 776443.1 \\
\hline LFC & 44248.17 & $\begin{array}{l}\text { Ioaindia (India } \\
\text { Olympic Games } \\
\text { Association) }\end{array}$ & $\# \mathrm{~N} / \mathrm{A}$ & 775933.2 \\
\hline unibirmingham & 41589.77 & $\begin{array}{l}\text { IndySport (UK } \\
\text { sports media) }\end{array}$ & \#N/A & 774696.6 \\
\hline birminghamcg22 & 40474.34 & $\begin{array}{l}\text { VickyDave02 (User } \\
\text { information can not } \\
\text { be identified via } \\
\text { user bio) }\end{array}$ & $\# \mathrm{~N} / \mathrm{A}$ & 772457.7 \\
\hline
\end{tabular}




\begin{tabular}{|l|l|l|l|l|}
\hline $\begin{array}{l}\text { Jassansi } \\
\text { photographer) }\end{array}$ & 38773.45 & $\begin{array}{l}\text { Detectiveplaty2 } \\
\text { (sport fan,India) }\end{array}$ & \#N/A & 757097.9 \\
\hline $\begin{array}{l}\text { Bbcwm (BBC } \\
\text { WM95.6) }\end{array}$ & 36372.62 & $\begin{array}{l}\text { Joeshendry (Joe } \\
\text { Hendry Show } \\
\text { Podcast) }\end{array}$ & \#N/A & 755254.2 \\
\hline 7NewsQueensland & 30961.99 & britishswimming & 1047.5 & 744216.6 \\
\hline ENG_feed_aswell & 30806.49 & $\begin{array}{l}\text { samstebbings18 } \\
\text { (WHRL player) }\end{array}$ & \#N/A & 723762 \\
\hline JeffreyGriff & 26133.18 & 7NewsSydney & \#N/A & 721343 \\
\hline Calacus_PR & 26037.56 & BBCSportScot & 2948.1 & 717057.6 \\
\hline BCCNewsRoom & 24381.86 & RodBamberry & 0 & 709201.1 \\
\hline CalzoMate & 20358.39 & PMOIndia & \#N/A & 698094 \\
\hline Fallout & 19900 & BBCWorld & \#N/A & 696811.2 \\
\hline CommGamesAUS & 19662.9 & $\begin{array}{l}\text { MarkACollett } \\
\text { (Political activist, } \\
\text { UK) }\end{array}$ & \#N/A & 683859 \\
\hline visit_bham & 17497.68 & Brad_Kul & \#N/A & 681139.8 \\
\hline BhamCityCouncil & 16936.94 & abcnews & \#N/A & 674433.3 \\
\hline tennisscotland & 16551.5 & Drusawasthi (India) & \#N/A & 660002.6 \\
\hline birminghammail & 14851.68 & $\begin{array}{l}\text { TedSouthey } \\
\text { (account inactive in } \\
\text { 2019) }\end{array}$ & \#N/A & 651768.4 \\
\hline
\end{tabular}

* Tweets that only contain the search terms "commonwealth games".

\section{Discussions}

This research empirically identified key stakeholder groups, their roles, positions, and network values in the twitter retweet network. Findings indicate that the governing bodies acted as focal actors to connect different communities during the game period but not prior to the games, and assumedly, will not function as focal actors post games period. Large and medium sports associations and news agencies played vital roles in the information flow of a mega event, who were active both before and during the game time. Sports media were connected via gatekeepers (e.g., BBCsports). Findings echo 'Media plays an important role' in Mossberg \& Getz's (2006) study on stakeholder influence of event branding.

Findings of this research depict the structure of stakeholder network of the Commonwealth Games, the interaction of actors, and the formation of clusters in the mega event context. This 
research finds that the network was largely connected by geographical proximity of the key users and change overtime. In the pre-game period, the network was consisted of many loosely connected communities and at times cliques that had no connections to other major communities, resulting in fragmented, dispersed and decentralised network during the pregame period. The network became dense during the game time (or when there were key related events) but the connection of the key users remained geographically bounded. The fact that the network was largely intertwined based on geographical proximity was not surprising, as the key actors were sports media or sports associations with their subscribers and followers mainly from their own geographical regions.

This research also indicates an inadequate presence and impact of local government and DMOs in the network. Being one of the key stakeholder groups, they were not key actors and exerted little influence in the network. The only exception in this regard was perhaps Visit Birmingham, which emerged in the pre-game dataset but had limited influence in the duringgame twitter network. Local government of the host city and the tourism bureaus were either games planning and implementing bodies or close allies and collaborators. They were the investors and beneficiaries of the event. Opportunities arise to increase their presence and influence by being more active in the social media information dissemination and dialogues. By so doing, they would be able to maximize the use of the twitter network to raise destination awareness to fulfil the purpose of destination marketing via mega-events. Tourism bureaus and local city councils should actively participate in social media communication of the event and the host location by tweeting, following key accounts, retweeting, and engaging users of the gatekeepers. This would produce a more effective marketing and communication of events and the host location. Since sports news agencies play a key role, apart from official commonwealth games organizations, tourism bureaus/DMOs need to consider engaging these sports media to maximise the readership of their tweets. 
This research suggests that the host organization owning the event brand and the host city executing the event need to increase their interaction with media and other key influencers in the social media environment. Amount of interaction can enhance affective ties and cultivate consistency and perhaps homogeneity in branding the event. To form such consistency and partnerships, host organizations may strengthen their dedication in the social media environment by appointing a social media management team to develop a strategy, strengthen interaction, and build ties with key influencers. These mechanisms would maintain the event brand even during off-game times and should be conducive to media collaboration for the next games. This is in line with the principle that firms with more alliance partners will be more successful in general marketing (e.g., Powell, Koput, \&Smith-Doerr 1996). To maximize the benefits of networks on Twitter, the host organizations shall be more selective in which twitter accounts to connect to maximize partnerships.

Forming partnerships with key influencers will help improve the effects of online communication via the network. Actors with similarity are more likely to be chosen as partners (i.e., homophily, McPherson, Smith-Lovin, \& Cook 2001). Organizations that are in the same geographical location are more likely to be linked than users further apart. Geographical proximity plays a key driver of network formation. New users will connect to those that are geographically close but not necessarily the most central users in the network, although other factors may also apply. It may not be necessary for DMOs to occupy a central position in the network but maximise the gain by having their posts retweeted by key influencers in the network.

The structure of the network and the key influencers within the network were notably different over time, consistent to the major events at the time of the data collected. Clusters emerged or dissolved at different time periods through entry and exit of active users. Findings 
suggest that it is important to identify transit vs permeant key accounts in the network to understand the effectiveness of using the network for event communication and branding.

\section{Conclusion and Implications}

This paper identifies key stakeholder groups and active online influencers in communication of the Commonwealth Games on social media. Our research shows that event organizations and host cities must understand the co-creative capacity of these key influencers and reinvent their own organizational design to engage these key influencers at different event planning and implementation stages for co-branding to gain economic and non-economic benefits. Forming alliances with these influencers in the online social media space will help event host organizations and DMOs to create new legacy opportunities and obtain access to resources.

This research makes important contributions to social media research in the event context. Different from previous literature on co-branding that largely involve two ways between brands and consumers, event branding is centrally dominant by various stakeholders in the social media space with no conclusive comments on whom will be leading the branding process (Mossberg \& Getz 2006). Our research confirms such stakeholder co-creating approach and adds empirical evidences to the debate that in online network established by key stakeholders, host organizations and host cities can be at the periphery level while traditional sports association can continue leading the digital conversation. To increase the network value, DMOs and host cities should go beyond "finding common interests" approach by establishing partnership with stakeholders with high betweenness centrality scores for a mega event. To better facilitate the flow of information in the mega event, it requires two step approach as our study shows that strategies with key stakeholders first and then key stakeholder based on geographical proximately will influence users within its reach. 
This research systematically and visually maps the network relations of key users on social media in a mega sports event context. It indicates how well these major users interact in the flow of information. This paper applied analysis at two levels. The analysis was first done at the actor level which counted the number of ties of key users and computed the degree of distances to other key users. This is useful to identify key influencers and locate actors who are central to the network. The second analysis was done at the network level which visually presented number of ties in the network, density and centrality (betweenness). This helps measure the number of connections exist in the context to determine the interaction and information flow with the network. At the meso level various forms of proximity can be brought forward to explain why links are stronger or weaker between some accounts and not others. This research indicates that geographical proximity is a key driver for the current network structure and there are little signs that the current network involves social proximity (i.e., users connect to other users with whom they are socially connected). Social proximity on mega events' online network shall be actively built through shared interest, expertise, experience for social connectedness. As such, the research provides a fundamental understanding of the effectiveness and configurations of the information flow in the social media environment in a mega event context.

Methodologically, this paper advances the current approaches in event studies by using SNA. In doing so, we have painted a complete picture of the roles and relations of the users arising out of a mega event context at both micro and macro levels. The graphical representations of the social media data provide an extraordinary level of detail, which depict the volumes, routes of information flow, complex relationships, and hierarchy in the overall network, which might not be possible to generate in traditional methodological approaches in event studies. Our study also highlights the methodological challenge when analyzing a big and complex data set - how we could effectively visualize them. As shown in our study, the 
retweet network contains hundreds of thousands of users with complex features form different relationship with other users. It is important for our tourism researchers to recognize the interactive features of big data visualization to gain both macro and micro analytics insights.

The findings provide important practical implications for event marketing and event-based destination marketing. Event governing, planning and executing bodies should identify early in the planning stage to allow adequate time to engage key stakeholders and influencers (e.g., sports agencies) for information input and sharing. It is a good idea to prioritise the engagement in the marking and communication commensurate with available resources. The stakeholder relationship in the mega events context is transitory. It can influence on an issue but not shift their overall perceptions or purposes. This is especially important for DMOs given their limited presence in the online social media space. DMOs need to consider which key influencers they should connect based on their availability, location and geographical space that these influencers cover so that host destinations could implement the event-based destination marketing strategies.

While acknowledging the important contributions, this study is not without limitations. First, this study only examines the prior and during games period, further longitudinal study that examines how network evolves across multiple mega events provide more insights into the network and network values of key stakeholders. Second, while preliminary findings suggest the importance of tweet content and sentiment in increasing the network value of DMOs, this research has not systematically examined such relationship. Further research by combing text mining of tweet and network value of key stakeholder would generate additional insights into the formation of the event social media network structure. 


\section{Reference}

Boyd, D., S. Golder, and G. Lotan. 2010. “Tweet, Tweet, Retweet: Conversational Aspects of Retweeting on Twitter.” In 2010 43rd Hawaii International Conference on System Sciences, 1-10. Honolulu, HI: IEEE. https://doi.org/10.1109/HICSS.2010.412.

Blondel, Vincent D., Jean-Loup Guillaume, Renaud Lambiotte, and Etienne Lefebvre. 2008. "Fast Unfolding of Communities in Large Networks." Journal of Statistical Mechanics: Theory and Experiment 2008 (10): P10008. https://doi.org/10.1088/1742$\underline{5468 / 2008 / 10 / \mathrm{P} 10008 .}$.

Borgatti, Stephen P., and Pacey C. Foster. 2003. “The Network Paradigm in Organizational Research: A Review and Typology.” Journal of Management 29 (6): 991-1013. https://doi.org/10.1016/S0149-2063(03)00087-4.

Brown, Jo, Amanda J. Broderick, and Nick Lee. 2007. "Word of Mouth Communication within Online Communities: Conceptualizing the Online Social Network." Journal of Interactive Marketing 21 (3): 2-20. https://doi.org/10.1002/dir.20082.

Brandes, U. (2001). A faster algorithm for betweenness centrality. Journal of mathematical sociology, 25(2), 163-177.

Brown, G., L. Chalip, L. Jago, and T. Mules. 2002. "The Sydney Olympics and Brand Australia.," 163-85.

Burt, Ronald S. 2009. Structural Holes: The Social Structure of Competition. Harvard University Press.

Chalip, Laurence, B. Christine Green, and Brad Hill. 2003. "Research and Reviews.” Journal of Sport Management 17: 214-234. 
Cheng, Mingming, and Carmel Foley. 2018. "The Sharing Economy and Digital Discrimination: The Case of Airbnb." International Journal of Hospitality Management 70 (March): 95-98. https://doi.org/10.1016/j.ijhm.2017.11.002.

Chu, Kar-Hai. Jennifer B. Unger, Jon-Patrick Allem, Monica Pattarroyo, Daniel Soto, Tess Boley Cruz, Haodong Yang, Ling Jiang, and Christopher C. Yang 2015. "Diffusion of Messages from an Electronic Cigarette Brand to Potential Users through Twitter.” PloS One 10 (12).

Felix, Reto, Philipp A. Rauschnabel, and Chris Hinsch. 2017. "Elements of Strategic Social Media Marketing: A Holistic Framework." Journal of Business Research 70 (January): 118-26. https://doi.org/10.1016/i.jbusres.2016.05.001.

Getz, Donald, and Sheranne Fairley. 2004. "Media Management at Sport Events for Destination Promotion: Case Studies and Concepts.” Text. 2004. https://doi.org/info:doi/10.3727/1525995031436926.

Kietzmann, Jan H., Kristopher Hermkens, Ian P. McCarthy, and Bruno S. Silvestre. 2011. "Social Media? Get Serious! Understanding the Functional Building Blocks of Social Media.” Business Horizons, SPECIAL ISSUE: SOCIAL MEDIA, 54 (3): 241-51. https://doi.org/10.1016/j.bushor.2011.01.005.

Kwak, Haewoon, Changhyun Lee, Hosung Park, and Sue Moon. 2010. "What Is Twitter, a Social Network or a News Media?" In Proceedings of the 19th International Conference on World Wide Web - WWW'10, 591. Raleigh, North Carolina, USA: ACM Press. https://doi.org/10.1145/1772690.1772751.

Leung, Daniel, Rob Law, Hubert van Hoof, and Dimitrios Buhalis. 2013. "Social Media in Tourism and Hospitality: A Literature Review.” Journal of Travel \& Tourism Marketing 30 (1-2): 3-22. https://doi.org/10.1080/10548408.2013.750919. 
Li, Xiang (Robert), and Kyriaki (Kiki) Kaplanidou. 2013. “The Impact of the 2008 Beijing Olympic Games on China's Destination Brand A U.S.-Based Examination.” Journal of Hospitality \& Tourism Research 37 (2): 237-61. https://doi.org/10.1177/1096348011425499.

Lin, Nan. 2002. Social Capital: A Theory of Social Structure and Action. Cambridge University Press.

Liu, Xinhai, Wolfgang Glänzel, and Bart De Moor. 2012. “Optimal and Hierarchical Clustering of Large-Scale Hybrid Networks for Scientific Mapping." Scientometrics 91 (2): 473-93. https://doi.org/10.1007/s11192-011-0600-x.

Lovejoy, Kristen, Richard D. Waters, and Gregory D. Saxton. 2012. “Engaging Stakeholders through Twitter: How Nonprofit Organizations Are Getting More out of 140 Characters or Less.” Public Relations Review, Strategically Managing International Communication in the 21st Century, 38 (2): 313-18. https://doi.org/10.1016/j.pubrev.2012.01.005.

Lund, Niels Frederik, Scott A. Cohen, and Caroline Scarles. 2018. "The Power of Social Media Storytelling in Destination Branding.” Journal of Destination Marketing \& Management 8 (June): 271-80. https://doi.org/10.1016/j.jdmm.2017.05.003.

Macnamara, Jim, and Ansgar Zerfass. 2012. "Social Media Communication in Organizations: The Challenges of Balancing Openness, Strategy, and Management.” International Journal of Strategic Communication 6 (4): 287-308. https://doi.org/10.1080/1553118X.2012.711402.

Majmundar, Anuja, Jon-Patrick Allem, Tess Boley Cruz, and Jennifer Beth Unger. 2018. “The Why We Retweet Scale.” PLOS ONE 13 (10): e0206076. https://doi.org/10.1371/journal.pone.0206076. 
Matthews, Doug. Special Event Production: the Process. Taylor \& Francis Group, 2015.

McPherson, Miller, Lynn Smith-Lovin, and James M Cook. 2001. "Birds of a Feather: Homophily in Social Networks.” Annual Review of Sociology 27 (1): 415-44. https://doi.org/10.1146/annurev.soc.27.1.415.

Mossberg, Lena, and Donald Getz. 2006. "Stakeholder Influences on the Ownership and Management of Festival Brands.” Scandinavian Journal of Hospitality and Tourism 6 (4): 308-26. https://doi.org/10.1080/15022250601003273.

Otte, Evelien, and Ronald Rousseau. 2002. "SNA: A Powerful Strategy, Also for the Information Sciences." Journal of Information Science 28 (6): 441-53. https://doi.org/10.1177/016555150202800601.

Powell, Walter W., Kenneth W. Koput, and Laurel Smith-Doerr. 1996. "Interorganizational Collaboration and the Locus of Innovation: Networks of Learning in Biotechnology." Administrative Science Quarterly 41 (1): 116-45. https://doi.org/10.2307/2393988.

Rowley, Timothy J. 1997. "Moving Beyond Dyadic Ties: A Network Theory of Stakeholder Influences.” Academy of Management Review 22 (4): 887-910. https://doi.org/10.5465/amr.1997.9711022107.

Saffer, Adam J., Erich J. Sommerfeldt, and Maureen Taylor. 2013. "The Effects of Organizational Twitter Interactivity on Organization-Public Relationships.” Public Relations Review 39 (3): 213-15. https://doi.org/10.1016/j.pubrev.2013.02.005.

Scott, John. 1991. "Networks of Corporate Power: A Comparative Assessment." Annual Review of Sociology 17 (1): 181-203. https://doi.org/10.1146/annurev.so.17.080191.001145. 
Swani, Kunal, Brian P. Brown, and George R. Milne. 2014. "Should Tweets Differ for B2B and B2C? An Analysis of Fortune 500 Companies' Twitter Communications.” Industrial Marketing Management 43 (5): 873-81. https://doi.org/10.1016/j.indmarman.2014.04.012.

Ter Wal, Anne L. J., and Ron A. Boschma. 2009. “Applying SNA in Economic Geography: Framing Some Key Analytic Issues.” The Annals of Regional Science 43 (3): 739-56. https://doi.org/10.1007/s00168-008-0258-3.

Wang, Ying, and Xin Jin. 2019. "Event-Based Destination Marketing: The Role of MegaEvents.” Event Management 23 (1): 109-18. https://doi.org/10.3727/152599518X15378845225384.

Washburn, Judith H., Brian D. Till, and Randi Priluck. 2000. "Co-branding: Brand Equity and Trial Effects.” Journal of Consumer Marketing 17 (7): 591-604. https://doi.org/10.1108/07363760010357796.

Wasserman, Stanley, Katherine Faust, and Stanley (University of Illinois Wasserman Urbana-Champaign). 1994. SNA: Methods and Applications. Cambridge University Press.

Whitelock, Jeryl, John W. Cadogan, Shintaro Okazaki, and Charles R. Taylor. 2013. "Social Media and International Advertising: Theoretical Challenges and Future Directions.” International Marketing Review, February. https://doi.org/10.1108/02651331311298573.

Xu, Yueying Hazel, IpKin Anthony Wong, and Xiuchang Sherry Tan. 2016. "Exploring Event Bundling: The Strategy and Its Impacts.” Tourism Management 52 (February): 455-67. https://doi.org/10.1016/j.tourman.2015.07.014. 